\title{
How to Perform and Interpret a Network Meta-Analysis for Indirect and Mixed Comparisons: Key Methodological Strategies
}

\author{
Como Realizar e Interpretar uma Meta-Análise em Rede para Comparaçóes Indiretas e \\ Mistas: Estratégias Metodológicas Fundamentais \\ Cómo Realizar e Interpretar una Meta-Análisis en Red para Comparaciones Indirectas y \\ Mixtas: Estrategias Metodológicas Fundamentales \\ Eduardo José Ferreira dos Santos*; Ricardo Jorge Oliveira Ferreira*; Andréa Ascenção Marques***
}

\begin{abstract}
Background: Meta-analysis techniques were traditionally used to assess the effectiveness and safety of a treatment through direct comparison with a single comparator. More recently, network meta-analyses allowed the comparison of multiple interventions and the incorporation of clinical evidence of direct and indirect comparisons. We consider it relevant to address the main methodological considerations on this theme because of its topicality.

Objectives: To demonstrate how to perform and interpret a network meta-analysis for indirect and mixed comparisons.

Main topics under analysis: We present some key concepts of a network meta-analysis for indirect and mixed comparisons and the assumptions for its application. We point out some of the methodological challenges and opportunities for application of this statistical technique resulting from the theoretical and methodological analysis of articles published in the last 5 years. Conclusions: The use of indirect and mixed comparisons to increase the statistical power is an essential contribution to the current meta-analysis techniques, allowing researchers to improve the process of synthesis and health professionals to apply the best available evidence.
\end{abstract}

Keywords: meta-analysis; review literature as topic; epidemiologic methods; evidence-based practice

\section{Resumo}

Enquadramento: Tradicionalmente as técnicas de meta-análise serviram para avaliar a eficácia e segurança de um tratamento através da comparação direta com um único comparador. Mais recentemente, as meta-análises em rede permitiram estabelecer comparações de múltiplas intervenções e incorporar evidência clínica de comparações diretas e indiretas. Pela atualidade do tema consideramos pertinente divulgar as suas principais considerações metodológicas.

Objetivos: Demonstrar como se realiza e interpreta uma meta-análise em rede para comparações indiretas e mistas.

Principais tópicos em análise: São apresentados alguns conceitos fundamentais relativos à meta-análise em rede para comparações indiretas e mistas e os pressupostos da sua aplicação. Apontamos alguns dos desafios metodológicos e oportunidades de aplicação desta técnica estatística, resultantes da análise teórica e metodológica de artigos publicados nos últimos 5 anos.

Conclusões: A introdução das comparações indiretas e das comparações mistas, que permitem aumentar o poder estatístico, apresentam-se como contributos indispensáveis para as atuais técnicas de meta-análise, permitindo aos investigadores incrementar o processo de síntese da melhor evidência disponível e aos profissionais de saúde a sua aplicação.

Palavras-chave: metanálise; literatura de revisão como assunto; métodos epidemiológicos; prática clínica baseada em evidências

\footnotetext{
* MSc., Research Associate of the Portugal Centre for Evidence Based Practice: a Collaborating Centre of the Joanna Briggs Institute. Nurse, Coimbra Hospital and University Center, EPE - Emergency Department, Campus HUC, 3000-075, Coimbra, Portugal [ejf.santos87@gmail.com]. Contribution to the article: literature search; elaboration of the practical example and the tables; literature analysis and discussion. Address for correspondence: Health Sciences Research Unit: Nursing, Avenida Bissay Barreto, Apartado 7001, 3046-851 Coimbra, Coimbra Portugal.

** MSc, RN, Coimbra Hospital and University Center, EPE - Rheumatology Department, Campus HUC, 3000075, Coimbra, Portugal [rferreira@ reumahuc org. Contribution to the article: elaboration of the tables;

literature analysis and discussion; article writing.
**** MSc., RN, Coimbra Hospital and University Center, EPE - Rheumatology Department, Campus HUC, 3000-075, Coimbra, Portugal [amarques@reumahuc.org]. Contribution to the article: literature analysis
} and discussion; article writing

\section{Resumen}

Marco contextual: Tradicionalmente las técnicas de metaanálisis sirvieron para evaluar la eficacia y seguridad de un tratamiento a través de la comparación directa con un único comparador. Más recientemente, las técnicas de metaanálisis en red permitieron comparar múltiples intervenciones e incorporar una prueba clínica de comparaciones directas e indirectas. Debido a su innovación, consideramos relevante divulgar sus principales consideraciones metodológicas.

Objetivos: Demostrar cómo se realiza e interpreta un metaanálisis en red para comparaciones indirectas y mixtas.

Principales temas en análisis: Se presentan algunos conceptos fundamentales relacionados con el metaanálisis en red para comparaciones indirectas y mixtas y los presupuestos de su aplicación. Asimismo, se señalan algunos de los desafíos metodológicos y de las oportunidades de aplicación de esta técnica estadística, que resultan del análisis teórico y metodológico de los artículos publicados en los últimos cinco años.

Conclusiones: La introducción de las comparaciones indirectas y las comparaciones mixtas, que permiten aumentar el poder estadístico, se presentan como contribuciones indispensables para las técnicas de metaanálisis actuales, lo que permite, a los investigadores, incrementar el proceso de síntesis de la mejor prueba disponible y, a los profesionales de la salud, su aplicación.

Palabras clave: metanálisis; literatura de revisión como asunto; métodos epidemiológicos; práctica clínica basada en la evidencia

Received for publication: 14.09 .15

Accepted for publication: 30.11 .15 


\section{Introduction}

Systematic reviews use pre-specified and explicit methods to identify, assess and summarize all available evidence with the purpose of addressing a clinical question (The Joanna Briggs Institute [JBI], 2012; Santos \& Cunha, 2013; JBI, 2014a). When made possible by the results of primary studies, systematic reviews may include a meta-analysis, i.e. a statistical analysis that allows combining the results from two or more separate studies (Rodrigues \& Ziegelmann, 2010; Li, Puhan, Vedula, Singh, \& Dickersin, 2011; JBI, 2012; Santos \& Cunha, 2013; JBI, 2014a). For decades, systematic reviews have only compared two interventions (B versus [vs] A), probably due to the lack of information reported in primary studies (Catalá-López \& Tobías, 2013). These reviews are only allowed for simple meta-analysis, which compared the effectiveness/safety of two interventions available for a given condition (Li et al., 2011).

In recent years, new analytical methods were developed that provide estimates of the relative effect (comparative effectiveness or safety) of multiple treatments through indirect comparisons, taking into account the full network of available studies (Li et al., 2011). Thus, the network meta-analysis within a systematic review refers to a meta-analysis in which three or more treatments are compared using both direct comparisons of interventions within randomized controlled trials (RCT) and indirect comparisons across RCTs based on a common comparator. These meta-analyzes are usually referred to in the literature as network meta-analysis, multiple treatments meta-analysis (MTM) or mixed treatments comparison meta-analysis (MTC) (Higgins \& Green, 2011; Li et al., 2011; Catalá-López \& Tobías, 2013; Tobías, Catalá-López, \& Roqué, 2014).

In this article, we present some key concepts related to the performance and interpretation of a network meta-analysis for indirect and mixed comparisons. To this end, we summarize their methodological challenges and opportunities for application resulting from the theoretical and methodological analysis of articles published in the last five years in this area of expertise. We specifically address the geometry of the evidence-based networks, the conditions for application - principles of transitivity and consistency - and provide an example of application and interpretation of the method.
Thus, this article aims to demonstrate how to perform and interpret a network meta-analysis for indirect and mixed comparisons, discussing the potential benefits of its implementation in the health area.

\section{Development}

Although network meta-analyzes are more complex and may be perceived as more prone to interpretation errors than traditional analyzes (Jansen \& Naci, 2013), both analyzes present assumptions that, when met, confer validity. In both methodologies, it is essential, among other aspects, to define the review question, specify the eligibility criteria, search for and select the studies correctly, as well as assess the risk of bias and the quality of the studies (Li et al., 2011; Mills et al., 2012). In addition, we cannot fail to mention that, despite being secondary studies, meta-analyzes may raise doubts regarding the compliance with ethical and legal principles, particularly in terms of the accuracy and adequacy of the findings (Li et al., 2011). The simplest application of a network meta-analysis for indirect and mixed comparisons consists of determining if treatment $\mathrm{B}$ is better than treatment $\mathrm{A}$, and if treatment $C$ is better than the same comparator $\mathrm{A}$, taking into account the lack of studies directly comparing B and C (Tobías et al., 2014; Figure 1A). Thus, several statistical methods can be used to perform indirect comparisons that can combine data from preliminary studies when these are limited or simply non-existent (Figure 1B), such as: the Bucher's method (Bucher, Guyatt, Griffith, \& Walter,1997), also called the method for adjusted indirect comparisons; the meta-regression (Bayesian and frequentist inference approaches); and the hierarchical Bayesian models based on the Markov chain Monte Carlo (Catalá-López \& Tobías, 2013; Tobías et al., 2014). In this study, we only demonstrate the Bucher's method due to its relative simplicity and for being the most commonly used method in the scientific community (Catalá-López \& Tobías, 2013; Tobías et al., 2014).

Mixed comparisons allow combining the estimates of direct and indirect comparisons, increasing the statistical power by reducing the confidence interval and increasing accuracy (Catalá-López \& Tobías, 2013; Tobías et al., 2014). However, it should be noted that this methodology retains the identity of each intervention and can only be performed when the 
interventions are similar across the primary studies (Higgins \& Green, 2011).

It is also a fact that network meta-analyzes are particularly suitable to address the main limitations of systematic reviews of reviews, also referred to in the literature as overviews of reviews (Higgins \& Green, 2011) or umbrella reviews (JBI, 2014b). However, they also assume that the studies of different comparisons are similar (Higgins \& Green, 2011; Santos \& Cunha, 2013). Indirect comparisons are not randomized comparisons; hence they should not be interpreted as such. They are essentially the result of the observations from all the trials and may suffer the biases characteristic of observational studies (Fronteira, 2013).

In situations in which direct and indirect comparisons can be performed, any use of indirect comparisons should complement and not replace the direct comparisons. Unless there are important limitations in RCTs, both approaches should be considered separately and the direct comparisons should prevail as the basis for drawing conclusions (Catalá-López \& Tobías, 2013; Tobías et al., 2014). In this process, it is clearly important that the team of reviewers should include a reviewer expert in statistics of secondary studies and predominantly of meta-analysis (Santos \& Cunha, 2013). In terms of statistical software to run network meta-analyzes, several commercial programs (with copyright) are currently available, such as STATA and SAS. Other open source programs are also available, such as OpenBUGS, WinBUGS, R (Neupane, Richer, Bonner, Kibret, \& Beyene, 2014) or the Excel sheet created by Tobías et al. (2014).

\section{Geometry of Evidence-Based Networks}

Evidence-based networks demonstrate how treatments are compared. Therefore, each line connects two or more treatments and its presence indicates that a direct comparison was performed in at least one study (Catalá-López \& Tobías, 2013; Jansen \& Naci, 2013; Catalá-López, Tobías, Cameron, Moher, \& Hutton, 2014).

Figure 1C shows several examples of network geometry. The simpler networks compare two interventions (Figure 1C i). The star (Figure 1C ii) and chain (Figure $1 \mathrm{C}$ iii) networks allow making indirect comparisons between treatments (Catalá-López \& Tobías, 2013; Jansen \& Naci, 2013; Catalá-Lopez et al., 2014). A classic example of a star network is when several RCTs have a common comparator (for example, a placebo). By using this example, we can establish indirect comparisons for A-C, C-D and A-D (Figure $1 \mathrm{C}$ ii). It is worth mentioning that there are more complex network models (Figure $1 \mathrm{C}$ iv) that require the use of more complex regression models.
1A

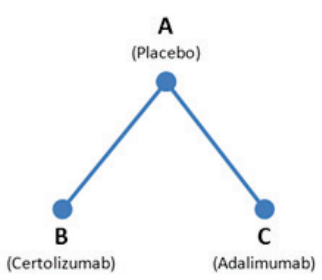

1B

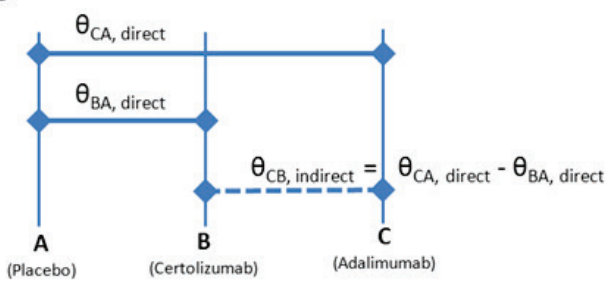

$1 C$

i

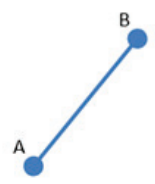

ii

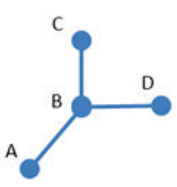

iii

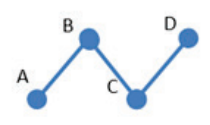

iv

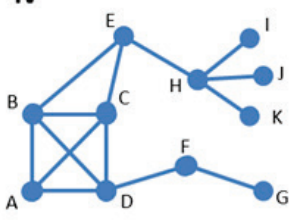

Source: Adapted from Catalá-López \& Tobías (2013, p. 183)

Figure 1. 1A - Example of direct comparisons; 1B - Example of indirect comparisons;

1C - Example of geometry of evidence-based networks. 


\section{Indirect and Mixed Comparisons}

Within the scope of a systematic review with meta-analysis for direct comparisons aiming at comparing the effectiveness (effect size $\theta$ ) of treatment $B$ in relation to treatment $\mathrm{A}\left(\theta_{A B}\right.$ direct $)$ and treatment $\mathrm{C}$ with the same comparator $\mathrm{A}\left(\theta_{A C}\right.$ direct $)$, and in the absence of studies directly comparing $\mathrm{B}$ and $\mathrm{C}$, it is possible, namely through the Bucher's method, to establish an indirect comparison and obtain an estimate of the effect size between $\mathrm{B}$ and $\mathrm{C}\left(\theta_{B C}\right.$ indirect), designated as adjusted indirect comparison (Bucher et al.,1997; Hoaglin et al., 2011; Miladinovic,

$2 A$

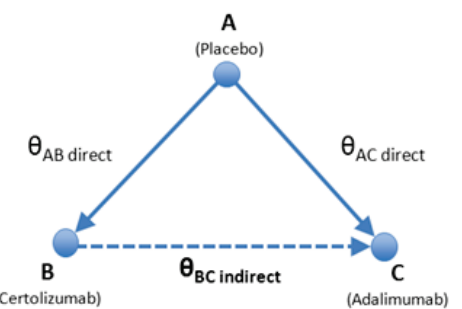

Method of calculation :

$\theta_{B C \text { indirect }}=\theta_{A C \text { direct }}-\theta_{A B \text { direct }}$

With 95\% Cl: $\theta_{B C \text { indirect }} \pm 1,96 \times s\left[\theta_{B C \text { indirect }}\right]$

Where: $S^{2}\left[\theta_{A C \text { direct }}\right]=\left[\left(C I_{\text {upper }}-C I_{\text {lower }}\right) / 3,92\right]^{2}$

$S^{2}\left[\theta_{A B \text { direct }}\right]=\left[\left(C I_{\text {upper }}-C I_{\text {lower }}\right) / 3,92\right]^{2}$

$S^{2}\left[\theta_{B C \text { indirect }}\right]=S^{2}\left[\theta_{A C \text { direct }}\right]+S^{2}\left[\theta_{A B \text { direct }}\right]$

$\left.S\left[\theta_{B C \text { indirect }}\right]=\sqrt{\left[S^{2}\right.}\left(\theta_{B C \text { indirect }}\right)\right]$
Hozo, Chaimani, \& Djulbegovic, 2014; Tobías et al., 2014). This method is described in Figure 2A.

In addition, even when the studies also have direct comparisons between $\mathrm{B}$ and $\mathrm{C}$, it is still possible to combine direct $\left(\theta_{B C \text { direct }}\right)$ and indirect $\left(\theta_{B C \text { indirect }}\right)$ comparisons, obtaining a mixed comparison $\left(\theta_{B C}\right.$ mixed; Figure 2B). This mixed comparison, which is possible through the calculation of its inverse variance, improves the accuracy of the estimates on the treatment effects (Bucher et al., 1997; Hoaglin et al., 2011; Miladinovic et al., 2014; Tobías et al., 2014).

2B

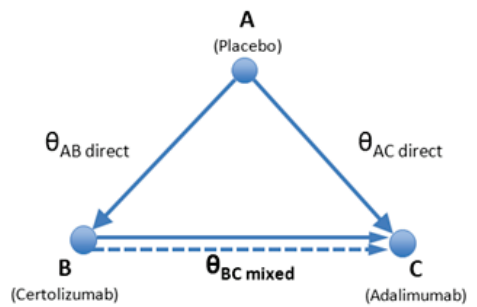

Method of calculation :

$\theta_{B C \text { mixed }}=\frac{\left(\theta_{B C \text { direct }} \times \frac{1}{S^{2}\left[\theta_{B C \text { direct }}\right]}\right)+\left(\theta_{B C \text { indirect }} \times \frac{1}{S^{2}\left[\theta_{B C \text { indirect }}\right]}\right)}{\left(\frac{1}{S^{2}\left[\theta_{B C \text { direct }}\right]}\right)+\left(\frac{1}{S^{2}\left[\theta_{B C \text { indirect }}\right]}\right)}$

With 95\% Cl: $\theta_{B C \text { mixed }} \pm 1,96 \times s\left[\theta_{B C \text { mixed }}\right]$

Where: $S^{2}\left[\theta_{B C \text { direct }}\right]=\left[\left(C I_{\text {upper }}-C I_{\text {lower }}\right) / 3,92\right]^{2}$

$S^{2}\left[\theta_{B C \text { mixed }}\right]=\frac{1}{\left(\frac{1}{S^{2}\left[\theta_{B C \text { direct }}\right]}\right)+\left(\frac{1}{S^{2}\left[\theta_{B C \text { indirect }}\right]}\right)}$

$\left.S\left[\theta_{B C \text { mixed }}\right]=\sqrt{\left[S^{2}\right.}\left(\theta_{B C \text { mixed }}\right)\right]$

Key:

$\theta$ - Effect size in additive scale; $S^{2}$ - Variance of the effect size; $S$ - Standard deviation of the effect size; $\mathrm{Cl}$ - Confidence Interval

Figure 2. Graphic presentation and formulas for indirect (2A) and mixed (2B) comparisons.

Adapted from Tobías et al., 2014.

Application Conditions: Principles of Transitivity and Consistency

Transitivity is a mandatory property (Madan et al., 2011; Higgins et al., 2012; Catalá-López \& Tobías, 2013) that assumes that the studies comparing $A$ and $\mathrm{C}$ are not related to $\mathrm{B}$ and that the studies comparing $\mathrm{A}$ and $\mathrm{B}$ are not related to $\mathrm{C}$, considering that there is no comparison between B and C. Interpretatively, we can say that if treatment $B$ is hypothetically better than $A$ and if $A$ is better than $C$, then we can presume that B is better than C (Catalá-López \& Tobías, 2013; Catalá-Lopez et al., 2014; Tobías et al., 2014).

As it is an observational analysis, there should be no differences in relation to the distribution of the effect modifiers across the analyzed studies, particularly regarding the participants (age, comorbidities...), the intervention (form of administration, dosage, follow-up...), the comparator or the outcome (Santos \& Cunha, 2013; Tobías et al., 2014).

In addition to transitivity, there should be a concordance between the evidence resulting from direct and indirect comparisons. This property is defined as consistency and aims at confirming that $\theta_{B C}$ direct is equal or similar to $\theta_{B C}$ indirect. One of the methods used to quantify this association is the inconsistency factor $\left(\mathrm{IF}=\theta_{B C \text { direct }}-\theta_{B C \text { indirect }}\right)$ to which a $\mathrm{Z}$ value and confidence intervals are assigned to check if there is statistical significance in the null hypothesis of 
consistency ( $\mathrm{IF}=0$; Bucher et al., 1997; Higgins et al., 2012; Catalá-López \& Tobías, 2013; Tobías et al., 2014). Although these properties (transitivity and consistency) are mandatory conditions for indirect comparisons and network meta-analyzes, it should be noted that, when performing the synthesis of evidence, it is essential to assess heterogeneity between the studies included (variability or differences between studies in the effect estimates). There are three types of heterogeneity: statistical heterogeneity (variation between the results of the studies that leads to differences in the results), methodological heterogeneity (differences in the designs of the studies included) and clinical heterogeneity (differences between the characteristics of the studies; JBI, 2012; Santos \& Cunha, 2013; JBI 2014a).

To determine the existence of heterogeneity, we can use Cochran's Q test and the $I^{2}$ statistics of Higgins and Thompson (Higgins \& Green, 2011). The Q-test assumes that there are no differences in the findings of primary studies - null hypothesis - and, if this is confirmed, the studies are considered homogeneous ( $p>0.05$; Rodrigues \& Ziegelmann, 2010; Higgins \& Green, 2011; Santos \& Cunha, 2013). The $I^{2}$ statistics varies between negative values and $100 \%$ : $I^{2}$ values close to $0 \%$ indicate no heterogeneity, close to $25 \%$ indicate low heterogeneity, close to $50 \%$ indicate moderate heterogeneity, and close to $75 \%$ indicate high heterogeneity (Rodrigues \& Ziegelmann, 2010; Higgins \& Green, 2011; Santos \& Cunha, 2013).

\section{Practical Example}

To more clearly and objectively illustrate the above mentioned concepts, we considered a fictitious example of a systematic review with meta-analysis seeking to assess the effectiveness of biological drugs (or biopharmaceuticals) in the treatment of rheumatoid arthritis, specifically comparing Adalimumab and Certolizumab. In the review process, four RCTs were selected that compare the effectiveness of Adalimumab against a placebo $(\mathrm{RR}=0.88 ; 95 \% \mathrm{CI}=0.60-1.1)$ and seven RCTs that compare the effectiveness of Certolizumab against a placebo ( $R R=1.2 ; 95 \%$ $\mathrm{CI}=0.71-77$ ). No primary studies were found that directly compare the effectiveness of Adalimumab with that of Certolizumab. It should be noted that we used the same comparator and intervention (form of administration, dosage, follow-up...), and that the comparison B vs A related to the Adalimumab vs placebo and that the comparison $C$ vs A related to the Certolizumab vs placebo. We emphasize that, prior to the process which we illustrate, the researchers had to first calculate the meta-analyzes of direct comparisons using specific statistical software (for example, RevMan, MASTARi-JBI, STATA, among others).

In view of these conditions, we could assume the presence of the principle of transitivity and calculate the indirect comparison between both treatments (Adalimumab vs Certolizumab).

In this example, we used the Excel sheet created by Tobías et al. (2014), available online at http:// metaanalisisenred.weebly.com/excel.html or at http://www.cochrane.es/?q=es/elaborar_RS.

After opening the worksheet (Figure 3), the researchers must choose the effect size that they previously used to calculate the direct comparisons, which, in our case, was the relative risk (RR) in the column of binary outcomes.

\section{INDIRECT \& MIXED TREATMENT COMPARISONS CALCULATOR}

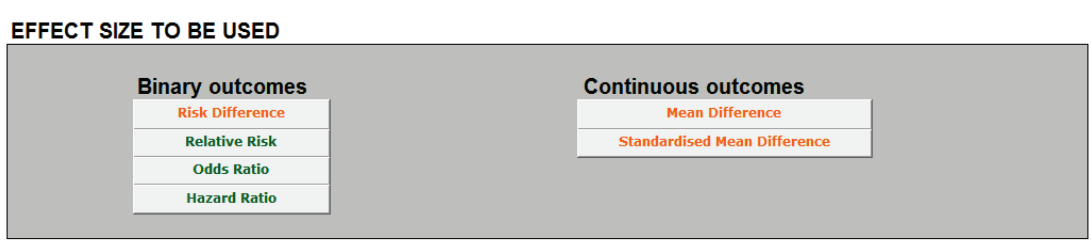

Version 1.0.1 7th October 2013

Figure 3. Main menu of the Excel sheet.

Then, the researchers must manually enter the data (relative risk and respective confidence intervals) relating to the above mentioned direct comparisons
( $\mathrm{B}$ vs $\mathrm{A}$ and $\mathrm{C}$ vs $\mathrm{A}$ ), and the indirect comparison is automatically calculated (Figure 4). 


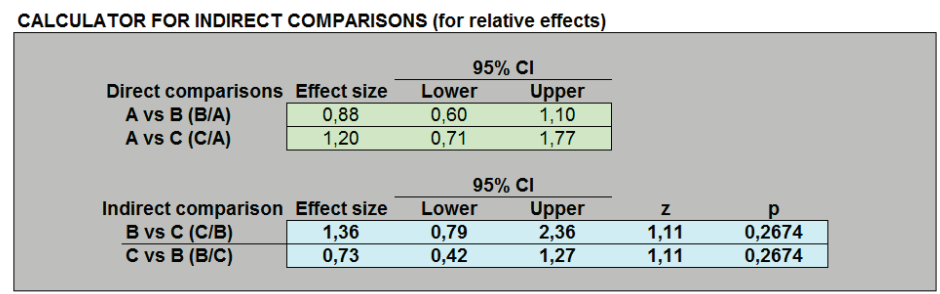

Figure 4. Screen with the results of indirect comparisons.

The results of the indirect comparison showed the two possibilities of comparisons ( $\mathrm{B}$ vs $\mathrm{C}$ and $\mathrm{C}$ vs $\mathrm{B}$ ). The first comparison (Adalimumab vs Certolizumab) had a relative risk of 0.36 points above $1(\mathrm{RR}=1.36$; $95 \%$ $\mathrm{CI}=0.79-2.36$ ), whereas the second comparison - inverse - had a relative risk of 0.27 points below $1(\mathrm{RR}=0.73 ; 95 \%$ $\mathrm{CI}=0.42-1.27)$. In addition, no statistically significant difference was found in any of the comparisons $(Z=1.11$; $p=0.2674$ ), which was possible to identify from the start since the confidence intervals ( $95 \% \mathrm{CI}$ ) include the value 1 between its upper and lower limit.

In the same example, but assuming that the review process included three RCTs that directly compared the effectiveness of Adalimumab with the effectiveness of Certolizumab (assuming $\mathrm{RR}=0.81 ; 95 \% \mathrm{CI}=0.51-1.21$ ), we are able to use mixed comparisons to improve the accuracy of the results. To this end, we must manually enter the data (RR and respective 95\% CIs) relating to direct and indirect comparisons, and the mixed comparison is automatically calculated (Figure 5). Regarding this procedure, the researchers should pay particular attention to the comparisons that are introduced, observing the order of the treatment and the treatment that is used as comparator so as to avoid statistical errors.

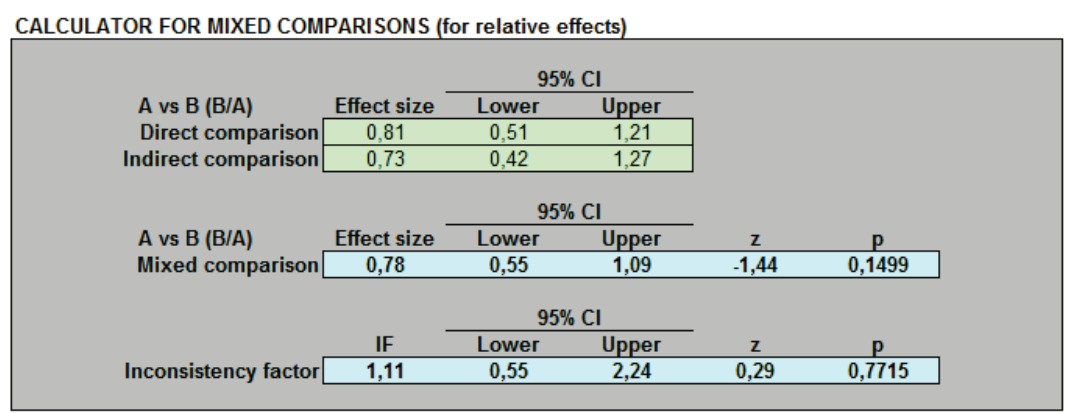

Figure 5. Screen with the results of mixed comparisons.

The results obtained through the mixed comparison generate new evidence and allow reducing the confidence intervals (improving accuracy). The results (Figure 5) showed that there was a lower risk in relation to the direct comparison in users treated with Adalimumab than with Certolizumab $(\mathrm{RR}=0.78$; 95\% CI=0.55-1.09), although without statistical significance $(p>0.05 ; z=-1.44 ; \quad p=0.1499)$. We would still have to critically analyze the inconsistency factor, which is also automatically calculated using the worksheet $(\mathrm{IF}=1.11 ; 95 \% \mathrm{CI}=0.55-2.24)$. The result indicates that we cannot reject the null hypothesis $\left(\mathrm{H}_{0}-\right.$ Comparisons are inconsistent) as there are no statistically significant differences $(z=0.29$; $p=0.7715)$. Thus, we can assume that the mixed comparison is consistent (the principle of consistency is preserved).

\section{Conclusion}

This article describes the basic aspects inherent to the methodologies of indirect comparisons through the Buchers' method and mixed comparisons. There are also other statistical methods to take into account that were not addressed throughout this study for editorial reasons, such as meta-regression and multivariate meta-analysis. These methods would require more 
advanced statistical software (for example, Stata or R). Network meta-analyzes are potentially relevant because they allow providing information in situations in which the primary evidence is scarce or inexistent, as well as providing more accurate effect estimates. Although some limitations to this methodology can be found in the literature, namely those related with the effect size of the calculated statistical estimate (upper or lower) or the fact that it can lead to biases (due to the diversity of methods and interpretations), a set of conditions, principles and procedures was identified whose compliance helps to overcome these limitations by providing valid and replicable results.

In conclusion, we believe that indirect and mixed comparisons are key contributions to the current meta-analysis techniques, allowing to increase the process of synthesis of the best available evidence and to assist in decision-making.

\section{Acknowledgements}

The authors would like to thank Daniela Cardoso, RN, and Mayra Santos, RN, for the critical review of the article and the constructive comments.

\section{References}

Bucher, H. C., Guyatt, G. H., Griffith, L. E., \& Walter, S. D. (1997). The results of direct and indirect treatment comparisons in meta-analysis of randomized controlled trials. Journal of Clinical Epidemiology, 50, 683-691. doi:10.1016/S08954356(97)00049-8

Catalá-López, F., \& Tobías, A. (2013). Síntesis de la evidencia clínica y metaanálisis en red con comparaciones indirectas. Medicina Clinica, 140(4), 182-187. doi: 10.1016/j. medcli.2012.09.013

Catalá-López, F., Tobías, A., Cameron, C., Moher, D., \& Hutton, B. (2014). Network meta-analysis for comparing treatment effects of multiple interventions: An introduction. Rheumatology International, 34(11), 1489-1496. doi: 10.1007/s00296-014-2994-2

Fronteira, I. (2013). Observational studies in the era of evidence based medicine: Short review on their relevance, taxonomy and designs. Acta Medica Portuguesa, 26(2), 161-70. Retrieved from http://www.actamedicaportuguesa.com/ revista/index.php/amp/article/view/3975/3223

Higgins, J. P. T., \& Green, S. (2011). Cochrane handbook for systematic reviews of interventions. London, England: The Cochrane Collaboration.
Higgins, J. P., Jackson, D., Barrett, J. K., Lu, G., Ades, A. E., \& White, I. R. (2012). Consistency and inconsistency in network meta-analysis: Concepts and models for multi-arm studies. Research Synthetesis Methods, 3, 98-110. doi: 10.1002/ jrsm.1044

Hoaglin, D. C., Hawkins, N., Jansen, J. P., Scott, D. A., Itzler, R., Cappelleri, J. C., ... Barrett, A. (2011). Conducting indirecttreatment-comparison and network-meta-analysis studies: Report of the ISPOR task force on indirect treatment comparisons good research practices: Part 2. Value in Health, 14(4), 429-437. doi:10.1016/j.jval.2011.01.011

Jansen, J. P., \& Naci, H. (2013). Is network meta-analysis as valid as standard pairwise meta-analysis?: It all depends on the distribution of effect modifiers. BMC Medicine, 11, 159. doi: 10.1186/1741-7015-11-159

Li, T., Puhan, M. A., Vedula, S. S., Singh, S., \& Dickersin, K. (2011). Network meta-analysis-highly attractive but more methodological research is needed. BMC Medicine, 9, 79. doi: 10.1186/1741-7015-9-79

Madan, J., Stevenson, M. D., Cooper, K. L., Ades, A. E., Whyte, S., \& Akehurst, R. (2011). Consistency between direct and indirect trial evidence: Is direct evidence always more reliable?. Value Health, 14(6), 953-960. doi: 10.1016/j.jval.2011.05.042

Miladinovic, B., Hozo, I., Chaimani, A., \& Djulbegovic, B. (2014). Indirect treatment comparison. Stata Journal, 14(1), 76-86.

Mills, E. J., Ioannidis, J. P., Thorlund, K., Schunemann, H. J., Puhan, M. A., \& Guyatt, G. H. (2012). How to use an article reporting a multiple treatment comparison meta-analysis. JAMA, 308(12), 1246-1253. doi:10.1001/2012.jama.11228

Neupane, B., Richer, D., Bonner, A. J., Kibret, T., \& Beyene, J. (2014). Network meta-analysis using $\mathrm{r}$ : A review of currently available automated packages. Plos One, 9(12), 1-17. doi:10.1371/journal.pone. 0115065

Rodrigues, C., \& Ziegelmann, P. (2010). Metanálise: Um guia prático. Revista HCPA, 30(4), 435-446. Retrieved from http:// hdl.handle.net/10183/24862

Santos, E., \& Cunha, M. (2013). Interpretação crítica dos resultados estatísticos de uma meta-análise: Estratégias metodológicas. Millenium, 44, 85-98. Retrieved from http:// www.ipv.pt/millenium/Millenium44/7.pdf

The Joanna Briggs Institute. (2012). User manual: Version 5.0 system for the unified management, assessment and review of information. Retrieved from http://joannabriggs.org/ assets/docs/sumari/SUMARI-V5-User-guide.pdf

The Joanna Briggs Institute. (2014a). Joanna Briggs Institute reviewers' manual: 2014 edition. Australia: Author. Retrieved from http://joannabriggs.org/assets/docs/sumari/ reviewersmanual-2014.pdf

The Joanna Briggs Institute. (2014b). Joanna Briggs Institute reviewers' manual: 2014 edition/supplement. Australia: Author. Retrieved from http://joannabriggs.org/assets/ 
docs/sumari/ReviewersManual-Methodology-JBI Umbrella\%20Reviews-2014.pdf

Tobías, A., Catalá-López, F., \& Roqué, M. (2014). Desarrollo de una hoja excel para metaanálisis de comparaciones indirectas y mixtas. Revista Espanhola de Salud Pública, 88(1), 5-15. Retrieved from http://scielo.isciii.es/scielo.php?pid $=\$ 1135$ $57272014000100002 \&$ script $=$ sci arttext 